Check for updates

Cite this: RSC Adv., 2019, 9, 5825

Received 29th December 2018 Accepted 11th February 2019

DOI: $10.1039 / c 8 r a 10638 j$

rsc.li/rsc-advances

\section{Phase transitions and chemical reactions of octahydro-1,3,5,7-tetranitro-1,3,5,7-tetrazocine under high pressure and high temperature $\uparrow$}

\author{
Dexiang Gao, ${ }^{a}$ Jin Huang, ${ }^{a}$ Xiaohuan Lin, ${ }^{a}$ Dongliang Yang, ${ }^{b}$ Yajie Wang*a \\ and Haiyan Zheng (iD *a
}

Octahydro-1,3,5,7-tetranitro-1,3,5,7-tetrazocine ( $H M X)$ is one of the most important energetic materials. Investigations on its phase transitions and chemical reactions under extreme conditions are very important to understand the explosion process and design new energetic materials. By using a diamond anvil cell combined with in situ Raman, IR and X-ray diffraction techniques up to a pressure of $\sim 40 \mathrm{GPa}$, we found that $\beta-\mathrm{HMX}$ undergoes four reversible phase transitions without any chemical reaction under external pressure at room temperature. Isostructural phase transitions emerge around $5 \mathrm{GPa}(\zeta-\mathrm{HMX})$ and 10-13 GPa $(\varepsilon-H M X)$, and another two phases emerge at $16 \mathrm{GPa}(\eta-\mathrm{HMX})$ and $27 \mathrm{GPa}(\phi-\mathrm{HMX})$. The unit cells of $\zeta-H M X$ and $\varepsilon-H M X$ were determined as $a=6.215 \AA, b=10.417 \AA, c=8.272 \AA, \beta=124.88^{\circ}$, $P 2_{1} / c$ at $6.2 \mathrm{GPa}$ and $a=6.130 \AA, b=9.846 \AA, c=8.258 \AA, \beta=125.06^{\circ}, P 2_{1} / c$ at $12.6 \mathrm{GPa}$, respectively. The crystal structures of $\beta, \zeta$, and $\varepsilon-H M X$ were obtained by Rietveld refinement, based on which the rotations of $\mathrm{NO}_{2}$ groups were found to be related to the phase transition at $5 \mathrm{GPa}$. Additionally, $\mathrm{HMX}$ decomposes at $8.7 \mathrm{GPa}$ and $300{ }^{\circ} \mathrm{C}$. Carbon dioxide, hydroxyl, imino and hydroxyimino groups were detected in the IR spectrum, which indicates that the reaction contains a hydrogen transfer process. Our investigation uncovers the structural variation of $\beta-H M X$ under external pressure and identifies the decomposition products under extreme conditions, which provides new insight to understand the detonation process of energetic materials.

\section{Introduction}

Energetic materials are a class of materials which can release the stored chemical energy in a short time upon external stimulation, including heat, shock or electrical current. The process will generate pressure up to $50 \mathrm{GPa}$ and temperature as high as $5500 \mathrm{~K},{ }^{1}$ which will induce the energetic materials to transform into different phases and affect the reaction process. Thus, investigations on the phase evolution and the followed decomposition reaction of energetic materials under extreme conditions are critical to understand the real detonation process and will be beneficial for designing the new energetic materials with high energy density and improved safety.

${ }^{a}$ Center for High Pressure Science and Technology Advanced Research, 100094, Beijing, China.E-mail:yajie.wang@hpstar.ac.cn; zhenghy@hpstar.ac.cn

${ }^{b}$ Institute of High Energy Physics, Chinese Academy of Sciences, Beijing 100049, China $\dagger$ Electronic supplementary information (ESI) available: Table S1: assignments of Raman modes of $\beta$-HMX at ambient pressure, room temperature. Table S2: assignments of IR modes of $\beta$-HMX at $1.0 \mathrm{GPa}$, room temperature. Table S3: the refined cell parameters under non-hydrostatic pressure conditions. Table S4: atomic coordinates of HMX at $6.2 \mathrm{GPa}$. Table S5: atomic coordinates of HMX at 12.6 GPa. Fig. S1: pressure dependences of IR-active modes of $\beta$-HMX at ambient temperature. Fig. S2: torsion angles of axial $\mathrm{NO}_{2}$ and equatorial $\mathrm{NO}_{2}$ under non-hydrostatic pressure condition. See DOI: 10.1039/c8ra10638j

Octahydro-1,3,5,7-tetranitro-1,3,5,7-tetrazocine

(HMX) (Fig. 1a) is one of the widely used energetic materials. At ambient pressure, it has four polymorphs $(\alpha, \beta, \gamma$ and $\delta)$, which can be obtained by controlling the crystallization rate in solution. ${ }^{2}$ The $\alpha, \beta$ and $\delta$ phases are pure crystalline phases, while the $\gamma$-HMX is a hydrate. ${ }^{3}$ In practice, the sensitivity and the detonation velocity are very important parameters, which are closely related to the solid-state structure. Among the fourth phases, $\beta$-HMX is the most favourable phase for military energetic materials because of the highest density and the lowest

(a)

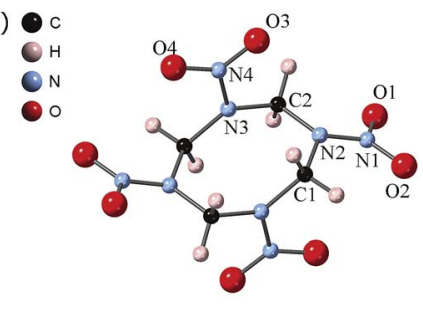

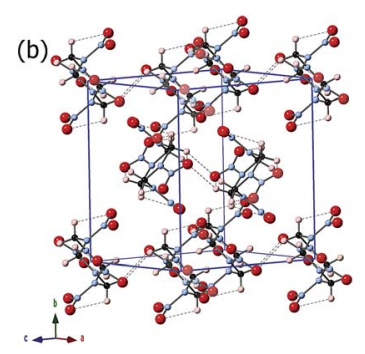

Fig. 1 The (a) molecular structure and (b) crystal structure of $\beta$-HMX at ambient condition. The dotted lines in (b) represent the inter/intramolecular hydrogen bonds. 
sensitivity. ${ }^{1}$ At ambient condition, $\beta$-HMX (monoclinic, $P 2_{1} / c$ ) is the most stable phase, with a unit cell $a=6.54 \AA$, $b=11.05 \AA$, $c$ $=8.70 \AA ; \beta=124.3^{\circ} .^{4}$ Its crystal structure including hydrogen atom positions was determined by neutron diffraction in $1970 .^{5}$ The $\beta$-HMX molecules are in chair conformation, with an inversion center at the center of the $\mathrm{C}_{4} \mathrm{~N}_{4}$ ring. All of the four carbon atoms and two $-\mathrm{N}-\mathrm{NO}_{2}$ groups are approximately on the chair plane, and two opposite $-\mathrm{N}-\mathrm{NO}_{2}$ groups tilted above and below the plane, respectively. The molecules form rows of chairs with the interstitial site against the molecules of four neighbored rows (Fig. 1b). Each molecule has six intramolecular hydrogen bonds between the $-\mathrm{NO}_{2}$ and $-\mathrm{CH}_{2}-$ groups, and 2-3 intermolecular hydrogen bonds for each $-\mathrm{NO}_{2}$ group, which forms a network through the crystal. At 102-104 ${ }^{\circ} \mathrm{C}, \beta$-HMX transforms to the $\alpha$ phase (orthorhombic, $F d d 2)^{4}$ and then to the $\delta$ phase (hexagonal, $P 6_{1}$ ) when heated at $160-164{ }^{\circ} \mathrm{C} .{ }^{6}$ The HMX molecules in both $\alpha$ and $\delta$ phase adopt the boat conformation, which have all four nitro groups on one side of the molecular plane.

Goetz et al. reported that the $\beta$-HMX was stable up to $5.4 \mathrm{GPa}$ at ambient temperature according to the in situ Raman and IR spectra. ${ }^{7}$ By using the Raman spectroscopy and X-ray diffraction, Yoo et al. investigated the phase evolution of the $\beta$-HMX under both quasi-hydrostatic condition to $45 \mathrm{GPa}$ and nonhydrostatic condition to $10 \mathrm{GPa}^{8}$ The pressure-volume relation displays two phase transitions under quasi-hydrostatic compression: one is at $12 \mathrm{GPa}$ with no apparent volume change ( $\varepsilon$-HMX) and the other is at $27 \mathrm{GPa}$ with a $4 \%$ volume change ( $\phi$-HMX). Under non-hydrostatic condition, the chemical reaction was reported at $6 \mathrm{GPa}$ as the strong increase of the background. Besides these two, Michael Pravica et al. reported another transition occurring near 5 GPa under non-hydrostatic condition. ${ }^{9}$ They also proposed that at 25 GPa HMX probably transformed to the known $\delta$ phase and there is no chemical reaction detected up to $30 \mathrm{GPa}$ at room temperature. By using the isentropic compression experiment technique, D. E. Hare et al. pointed out no obvious indication of the phase transition processing at $27 \mathrm{GPa}^{10}$ By using the same technique to compress HMX single crystals up to $50 \mathrm{GPa}$, Hooks. et al. also didn't find any evidences for the phase transition in $27 \mathrm{GPa}^{\mathbf{1 1}}$ Theoretically, by using isothermal-isobaric molecular dynamics (NPT-MD) simulation, an abrupt change for the volume and internal geometrical parameters was observed at $27 \mathrm{GPa}$ suggesting a phase transition. ${ }^{12}$ Lei Zhang et al. employed the firstprinciples method to predict that no $\beta-\delta / \varepsilon-\delta$ phase transition occurs at $27 \mathrm{GPa} .{ }^{13}$ When heated at high pressure, the $\beta$-HMX decomposes or after a phase transition to $\delta$-HMX experimentally. ${ }^{\mathbf{1 4}}$ Debashits Chakraborty et al. proposed three reaction mechanisms in the gas phase HMX according to the ab initio calculations, including the homolytic cleavage of $\mathrm{N}-\mathrm{N}$ bond to form $\mathrm{NO}_{2}$, the eliminations of $\mathrm{HONO}$ and the O-migration from one of the $\mathrm{NO}_{2}$ groups to neighbouring $\mathrm{C}$ atom. ${ }^{15}$ Gasper $\mathrm{J}$. Piermarini et al. reported that the pressure decreases the rate of thermal decomposition and they concluded that there might involve a ring expansion prior to bond scission. ${ }^{16}$ By employing the in situ infrared (IR) spectroscopy, $\mathrm{N}_{2} \mathrm{O}$ and $\mathrm{CO}_{2}$ were identified in the decomposition products and they found the pressure accelerates the decomposition at low-to-moderate pressure and decelerates the reaction at higher pressure. ${ }^{\mathbf{1 4}}$

Although HMX has been studied and used for at least 60 years, the phase transitions of $\beta$-HMX under extreme conditions were still controversial and its reaction mechanism is still not clear. All the known researches on the phase relation are based on the $P-V$ relations or the spectral results, lack of crystallographic results even in the low pressure range, which is actually very important to understand the structure evolution and chemical reaction. Furthermore, for the decomposition process, there are still no enough information about the products of HMX under variable high pressure and high temperature conditions.

In this paper, by combing multiple technologies including in situ Raman, IR, and X-ray diffraction (XRD), we investigated the phase transitions and decomposition of $\beta$-HMX under nonhydrostatic pressure up to $40 \mathrm{GPa}$. Four new phases named $\zeta$ HMX, $\varepsilon$-HMX, $\eta$-HMX and $\phi$-HMX were indentified and the crystal structures of $\beta, \zeta$ and $\varepsilon$-HMX were determined. We found the rotation of $\mathrm{NO}_{2}$ groups was closely related to the phase transition at $5 \mathrm{GPa}$ from $\beta$ to $\zeta$-HMX. Additionally, HMX is decomposed at $8.7 \mathrm{GPa}$ and $300{ }^{\circ} \mathrm{C}$, and produces carbon dioxide, hydroxyl, imino and hydroxyimino groups, which indicates that the reaction contains the hydrogen transfer process.

\section{Experimental methods}

The HMX sample used for the Raman, IR and synchrotron XRD measurements was gently ground in an agate mortar. The sample was identified as $\beta$-HMX by powder XRD analysis on a PANalytical Empyrean diffractometer ( $\mathrm{Cu} \mathrm{K} \alpha$ radiation), and no impurity was detected. A symmetric diamond anvil cell with $d_{\text {culet }}=300 \mu \mathrm{m}$ was employed to apply pressure. For the in situ IR measurement, a pair of type II diamonds was used. A T-301 stainless steel gasket was pre-indented to a thickness of 40 $\mu \mathrm{m}$ and a hole with diameter of $100 \mu \mathrm{m}$ was drilled to serve as the sample chamber. In situ Raman spectra were collected on a commercial Renishaw Raman microscope with excitation laser wavelength at $488 \mathrm{~nm}$. In situ IR experiments were carried out on a Bruker VERTEX 70v with HYPERION 2000 microscope. A Globar was used as a conventional source. The spectra were collected in a transmission mode in the range of $600-4000 \mathrm{~cm}^{-1}$ with a resolution of $2 \mathrm{~cm}^{-1}$. The aperture was set to $20 \times 20 \mu \mathrm{m}^{2}$ and the absorption of the diamond anvils of the same area was used as the background. No pressure media was added during the Raman and IR measurements. For the in situ IR measurements under high pressure and room temperature, $\mathrm{KBr}$ pellet was used to optimize the thickness of the sample for good absorption signals. The in situ IR spectra of HMX without $\mathrm{KBr}$ were also measured and no difference was observed.

A resistive heater was wrapped around the cell for heating and the temperature was measured by using a calibrated thermocouple (K-type) placed on the gasket. To avoid the interference of $\mathrm{KBr}$, pure $\mathrm{HMX}$ was loaded into the gasket when measuring the IR spectra under high pressure and high temperature conditions. The sample was compressed to 
$\sim 6.6 \mathrm{GPa}$ and heated up to $200{ }^{\circ} \mathrm{C}$ and $300{ }^{\circ} \mathrm{C}$, respectively. The IR spectra were collected after cooling down to the room temperature.

In situ high pressure angular-dispersive X-ray diffraction (ADXRD) data up to $40 \mathrm{GPa}$ were collected at the High Pressure Station at $4 \mathrm{~W} 2$ beamline of the Beijing Synchrotron Radiation Facility (BSRF). The incident X-ray was monochromated to 0.6199 $\AA$ and a Pilatus detector calibrated by a $\mathrm{CeO}_{2}$ standard sample was used. The beam size was $\sim 20 \times 30 \mu \mathrm{m}^{2}$. The data was reduced by using the Dioptas software. ${ }^{17}$ The pressures of the in situ Raman, IR spectroscopy and XRD measurements were calibrated by the ruby fluorescence. ${ }^{18}$ The crystal structures and atomic positions of $\beta$-HMX under high pressure were determined by Rietveld refinement using the Jana 2006 package. ${ }^{19}$

\section{Results and discussion}

\section{Raman spectra of $\beta$-HMX under non-hydrostatic high pressure}

Fig. 2 displays Raman spectra of $\beta$-HMX under non-hydrostatic pressure condition up to $40 \mathrm{GPa}$. The frequency shifts of the Raman modes with increasing pressure are shown in Fig. 3. The Raman modes at ambient pressure are assigned according to the calculated results of the reference and shown in Table S1. $\dagger^{20}$ The peaks below $400 \mathrm{~cm}^{-1}$ correspond to the interspersed lattice phonons. The peaks related to the $\mathrm{C}_{4} \mathrm{~N}_{4}$ ring are mainly in the following regions: (1) distortions and deformations of the $\mathrm{C}_{4} \mathrm{~N}_{4}$ ring (400-800 $\mathrm{cm}^{-1}$ ); (2) C-N stretching of the $\mathrm{C}_{4} \mathrm{~N}_{4}$ ring (ring-stretching motion) and $\mathrm{N}-\mathrm{N}$ stretching $\left(800-1240 \mathrm{~cm}^{-1}\right.$ );
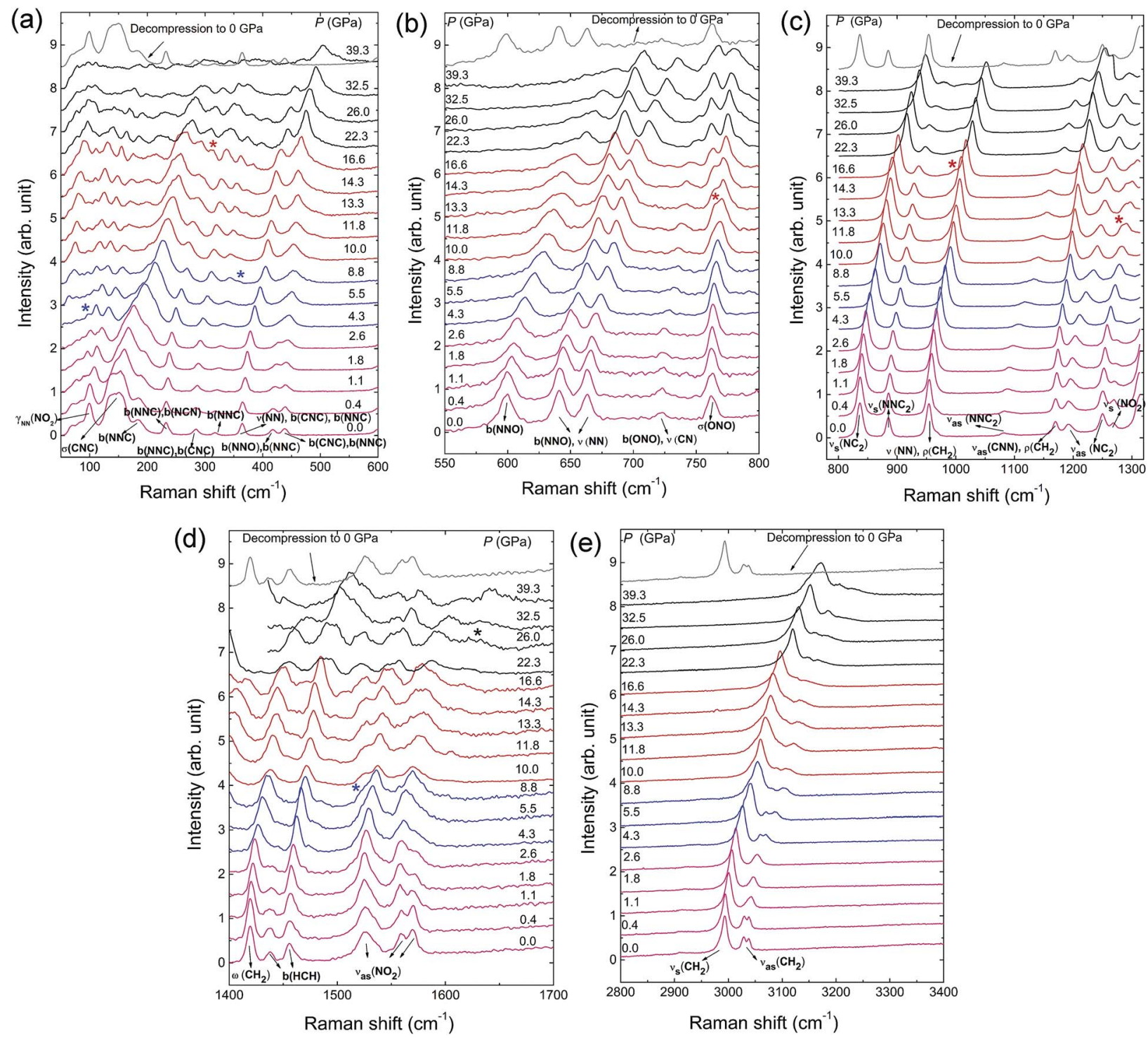

Fig. 2 Raman spectra of $\beta$-HMX under non-hydrostatic pressure up to $40 \mathrm{GPa}$ and ambient pressure after decompression. (a) $100-600 \mathrm{~cm}^{-1}$, (b) $550-800 \mathrm{~cm}^{-1}$, (c) $800-1300 \mathrm{~cm}^{-1}$, (d) $1400-1700 \mathrm{~cm}^{-1}$, (e) $2800-3400 \mathrm{~cm}^{-1}$ at selected pressures. The new peaks are marked by the asterisks. The Raman modes abbreviations are as following: $b(X Y Z): X-Y-Z$ bending vibration; $\nu_{\text {as }}\left(X Y_{2}\right): Y-X-Y$ asymmetric stretching vibration; $\nu_{\text {as }}\left(X X Y_{2}\right): X-X-Y_{2}$ asymmetric stretching vibration; $\nu_{s}\left(X Y_{2}\right): Y-X-Y$ symmetric stretching vibration; $\nu_{s}\left(X X Y_{2}\right): X-X-Y_{2}$ symmetric stretching vibration; $\rho\left(X Y_{2}\right)$ : $X Y_{2}$ rocking vibration in $X Y_{2}$ plane; $\sigma\left(X Y_{2}\right)$ : $X$ atom rocking vibration out of $X Y_{2}$ plane; $\omega\left(X Y_{2}\right)$ : $Y_{2}$ rocking vibration out of $X Y_{2}$ plane; $\gamma_{N N}\left(X Y_{2}\right): X Y_{2}$ twisting vibration about $N-N$ bond. ${ }^{20}$ 

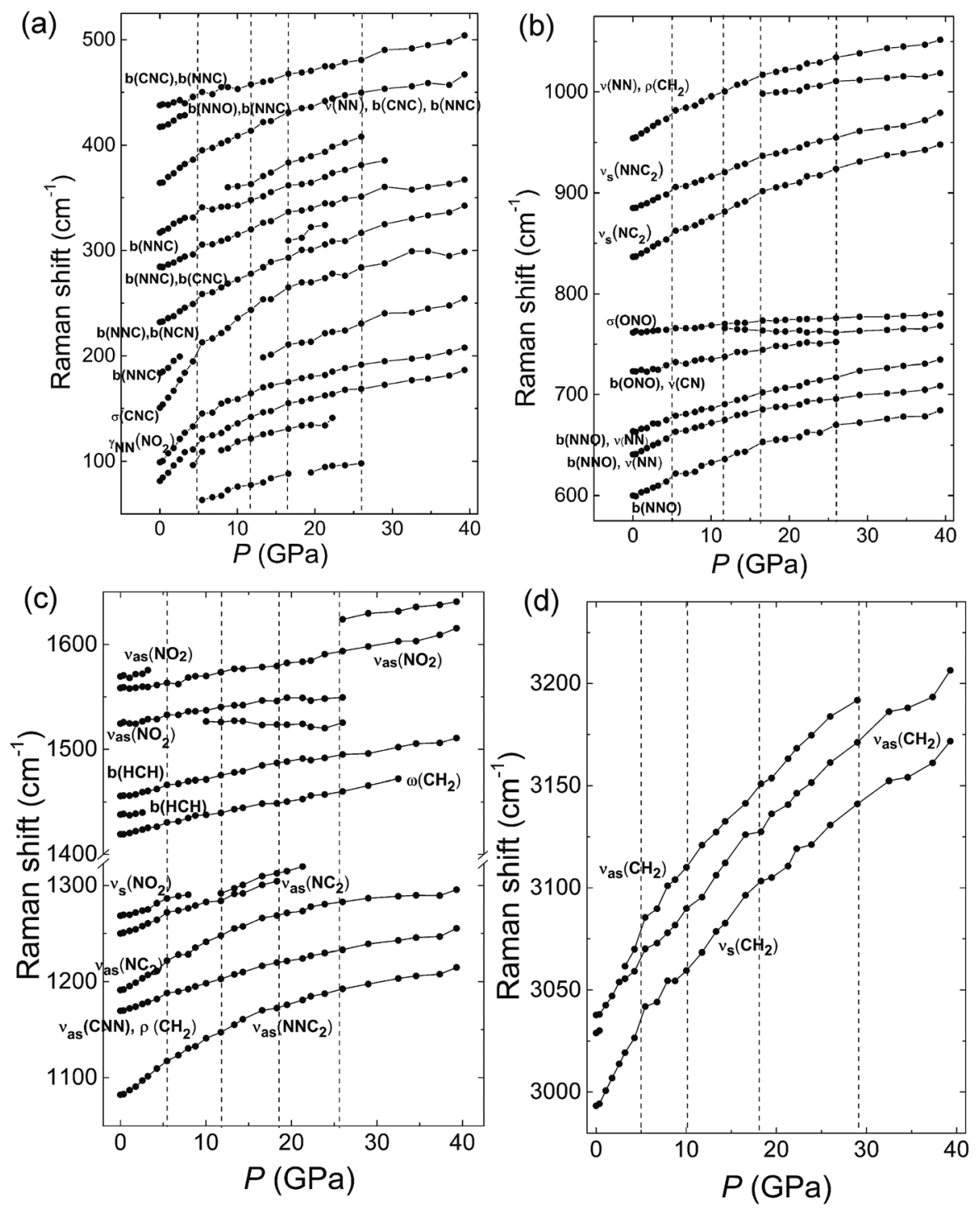

Fig. 3 Raman frequency shifts of $\beta-\mathrm{HMX}$ at room temperature as a function of pressure in the range of (a) $100-500 \mathrm{~cm}^{-1},(\mathrm{~b}) 600-1050 \mathrm{~cm}^{-1}$, (c) $1050-1650 \mathrm{~cm}^{-1}$, and (d) $3000-3250 \mathrm{~cm}^{-1}$. The symbol of the different vibration modes can be found in the caption of Fig. 2 . Four vertical lines represent boundaries of different phases. Raman spectra of $\beta$ - $\mathrm{HMX}$ under non-hydrostatic high pressure.

(3) deformation of $\mathrm{CH}_{2}$ moieties in $\mathrm{C}_{4} \mathrm{~N}_{4} \operatorname{ring}\left(1350-1500 \mathrm{~cm}^{-1}\right)$; (4) $\mathrm{C}-\mathrm{H}$ bond stretching $\left(2900-3100 \mathrm{~cm}^{-1}\right.$ ). For the $\mathrm{NO}_{2}$ moieties, two kinds of modes are observed in the Raman spectra, one is the distortion mode at $762 \mathrm{~cm}^{-1}$ and the others are the stretching modes, the symmetric $\left(1269 \mathrm{~cm}^{-1}\right)$ and asymmetric stretches (1526-1570 $\mathrm{cm}^{-1}$ ). Upon compression, all the Raman modes show obvious blue shifts because of the increasing interatomic interactions. ${ }^{21}$ As shown in Fig. 2, at low pressure region below $5 \mathrm{GPa}$, a new peak marked by asterisks appears at $98 \mathrm{~cm}^{-1}$ around $4.3 \mathrm{GPa}$. Meanwhile, as displayed in Fig. 3, a discontinuity is observed at $5 \mathrm{GPa}$. It indicates the phase transition from $\beta$-HMX to $\zeta$-HMX. Additionally, it also should be noticed that the two peaks assigned to $\mathrm{H}-\mathrm{C}-\mathrm{H}$ asymmetric stretching $\left(3028 \mathrm{~cm}^{-1}\right.$ and $\left.3036 \mathrm{~cm}^{-1}\right)$ shift to high frequency at different rates (Fig. 3d). The low frequency $\mathrm{H}-\mathrm{C}-\mathrm{H}$ asymmetric stretching mode shifts faster than the high frequency one, which makes these two peaks overlap at $1.1 \mathrm{GPa}$ and then separate at 3.2 GPa. This suggests that the $\mathrm{H}-\mathrm{C}-\mathrm{H}$ asymmetric stretching mode at low frequency is more sensitive to pressure. By further compression, several distinct changes are observed above $8.8 \mathrm{GPa}$, including a new mode $\left(360 \mathrm{~cm}^{-1}\right)$ next to the bending mode of the $\mathrm{N}-\mathrm{N}-\mathrm{C}$ or $\mathrm{N}-\mathrm{N}-\mathrm{O}$ bond and a new peak at $1525 \mathrm{~cm}^{-1}$ on the shoulder of $\nu_{\text {as }}\left(\mathrm{NO}_{2}\right)$ (asymmetric stretches of the $\mathrm{NO}_{2}$ moieties). The new peak at $1525 \mathrm{~cm}^{-1}$ shows red shift upon further compression, which is probably attributed to the strengthened intermolecular hydrogen bond during compression. ${ }^{22}$ Furthermore, the peaks $\left(765 \mathrm{~cm}^{-1}\right.$ and $\left.1285 \mathrm{~cm}^{-1}\right)$ ascribed to the $\sigma(\mathrm{ONO})\left(\mathrm{O}-\mathrm{N}-\mathrm{O}\right.$ wagging vibration) and $\nu_{\text {as }}\left(\mathrm{NC}_{2}\right)$ (the asymmetric stretches of the $\mathrm{C}-\mathrm{N}-\mathrm{C}$ bond) split significantly when compressed to $11.8 \mathrm{GPa}$. The shoulder in the low frequency of $\sigma(\mathrm{ONO})$ also shows red shift upon further compression. All the new modes indicate that the second phase transition from $\zeta$-HMX to $\varepsilon$-HMX occurs. The phase transition is very sluggish over a broad pressure range from 8.8 to $11.8 \mathrm{GPa}$. 
This may be because of the non-hydrostatic pressure condition, or the limited difference between their Gibbs free energies. With further compression, the third phase transition from $\varepsilon^{-}$ HMX to $\eta$-HMX emerges at 16.6 GPa. Above 16.6 GPa, a new peak emerges at $312 \mathrm{~cm}^{-1}$ at the low frequency side of $\mathrm{N}-\mathrm{N}-\mathrm{C}$ (or $\mathrm{C}-\mathrm{N}-\mathrm{C}$ ) bending modes. Meanwhile, a shoulder in the region of the $\mathrm{N}-\mathrm{N}$ stretching modes emerges at $1000 \mathrm{~cm}^{-1}$. At $26 \mathrm{GPa}$, a very weak new peak can be found around $1600 \mathrm{~cm}^{-1}$ and a lot of peaks disappeared at this pressure (Fig. 3), this might suggest another phase transition from $\eta$-HMX to $\phi$-HMX. Solid evidences of this phase transition can be found from the in situ XRD data shown below and consistent with the literatures. ${ }^{8,9}$

Therefore, from the in situ Raman spectra under high pressure, four phase transitions are concluded with the transition boundaries at $4.3 \mathrm{GPa}, 12 \mathrm{GPa}, 17 \mathrm{GPa}$ and $26 \mathrm{GPa}$. When decompressed to ambient pressure, the Raman spectrum is the same as that collected before compression. This suggests that all the phase transitions are reversible and there is no chemical reaction happened up to $39.3 \mathrm{GPa}$ under non-hydrostatic pressure condition. All the phase transitions are related to the bending or stretching modes of the $\mathrm{N}-\mathrm{N}-\mathrm{C}, \mathrm{C}-\mathrm{N}-\mathrm{C}$ or $\mathrm{NO}_{2}$. This suggests that these phase transitions rise from the distortion of the $\mathrm{C}_{4} \mathrm{~N}_{4}$ ring of the HMX, which may result in the reorientation of the $\mathrm{NO}_{2}$ groups. More evidences are discussed later in the in situ high pressure IR and XRD investigations. The red shift of the new peaks related to stretching mode $\left(\nu_{\text {as }}\left(\mathrm{NO}_{2}\right)\right)$ and wagging vibration $(\sigma(\mathrm{ONO}))$ of $\mathrm{NO}_{2}$ moieties indicates the enhancement of hydrogen bonds of $\mathrm{NO}_{2}$ during compression.

\section{IR spectra of $\beta$-HMX under non-hydrostatic high pressure}

In situ IR spectra were also collected under non-hydrostatic pressure condition up to $40.2 \mathrm{GPa}$. Table $\mathrm{S} 2 \uparrow$ gives the assignment of the IR modes of the $\beta$-HMX at $1.0 \mathrm{GPa}$ according to the calculation results of the ref. 20 In the region from 604$660 \mathrm{~cm}^{-1}$, the peaks are mainly from distortions and deformations of the $\mathrm{C}_{4} \mathrm{~N}_{4}$ ring, including the bending of $\mathrm{N}-\mathrm{N}-\mathrm{O}$ angles and the stretching of $\mathrm{N}-\mathrm{N}$ bonds. The peaks located in the region of $700-800 \mathrm{~cm}^{-1}$ are ascribed to the distortion of the ring and $\mathrm{NO}_{2}$ moieties. Except for the peak at $937 \mathrm{~cm}^{-1}$, all the peaks in the region $800-970 \mathrm{~cm}^{-1}$ are related to the $\mathrm{C}-\mathrm{N}$ stretching of the $\mathrm{C}_{4} \mathrm{~N}_{4}$ ring (ring stretching motion) and the peaks in the region of $970-1240 \mathrm{~cm}^{-1}$ are recognized as the stretching of $\mathrm{N}-\mathrm{N}$ and $\mathrm{C}-\mathrm{N}$ bonds. The peaks in 1350$1500 \mathrm{~cm}^{-1}$ are related to the deformation of $\mathrm{CH}_{2}$ in $\mathrm{C}_{4} \mathrm{~N}_{4}$ ring. The peaks in $1500-1700 \mathrm{~cm}^{-1}$ and $2900-3100 \mathrm{~cm}^{-1}$ are ascribed to the asymmetric stretches of the $-\mathrm{NO}_{2}$, and the $\mathrm{C}-\mathrm{H}$ bond stretching respectively.

As displayed in Fig. 4, no remarkable changes are observed in the IR spectral patterns but shift to high frequency below $12 \mathrm{GPa}$. Above $12.2 \mathrm{GPa}$, a shoulder peak $\left(978 \mathrm{~cm}^{-1}\right)$ in the region of $\nu_{\text {as }}(\mathrm{NNC})$ (the asymmetric stretches of the $\mathrm{N}-\mathrm{N}-\mathrm{C}$ ) is observed. Meanwhile, a new mode emerges at $665 \mathrm{~cm}^{-1}$ in highfrequency region of $\mathrm{N}-\mathrm{N}-\mathrm{O}$ bending vibration and two peaks appear in the shoulder of $\nu_{\mathrm{s}}\left(\mathrm{NO}_{2}\right)$ at $1338 \mathrm{~cm}^{-1}$ and $1612 \mathrm{~cm}^{-1}$. The results correspond to the phase transition from $\zeta$-HMX to $\varepsilon^{-}$ HMX. All the changes are related to the $\mathrm{NO}_{2}$ moieties, suggesting the phase transition may contain the distortion of the $\mathrm{NO}_{2}$ groups. Under further compression to $17.1 \mathrm{GPa}$, a new peak $\left(1479 \mathrm{~cm}^{-1}\right)$ next to the bending mode of the $\mathrm{H}-\mathrm{C}-\mathrm{H}$ emerges, while several peaks $\left(773 \mathrm{~cm}^{-1}, 876 \mathrm{~cm}^{-1}\right)$ disappear around $17.1 \mathrm{GPa}$. This corresponds to the transition from $\varepsilon$-HMX to $\eta$ HMX. After decompression from $40 \mathrm{GPa}$, all of the peaks are the same as the $\beta$-HMX, which also indicates all the phase transitions in our experiment are reversible without any chemical reactions. The frequency shifts of the IR modes with increasing pressures are shown in Fig. S1.† Similar to the Raman results, as Fig. S1c $\dagger$ displayed, the two peaks assigned to $\mathrm{H}-\mathrm{C}-\mathrm{H}$
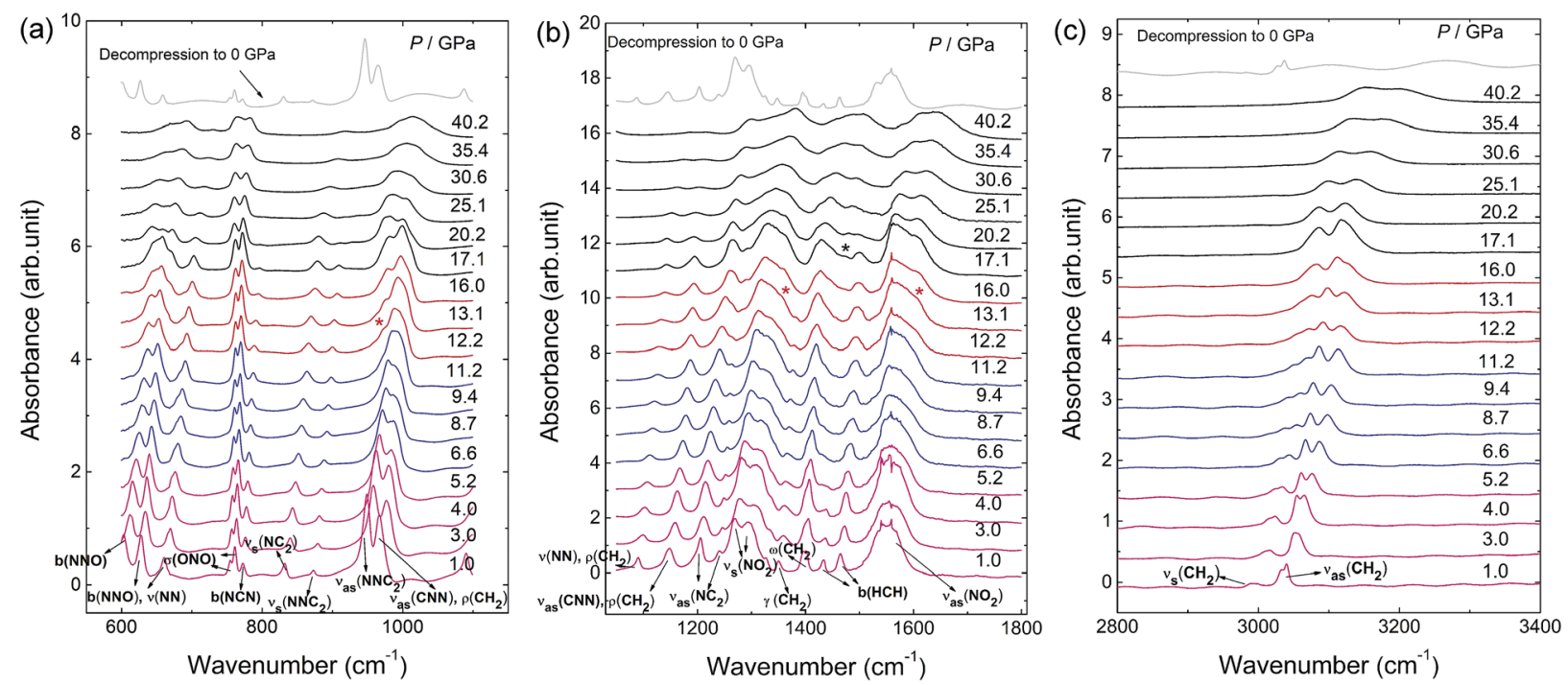

Fig. 4 In situ IR spectra of $\beta$-HMX under non-hydrostatic pressure condition up to $40 \mathrm{GPa}$ and ambient pressure after decompression in the spectra region of (a) 600-1100, (b) 1050-1800 and (c) 2800-3400 $\mathrm{cm}^{-1}$ at selected pressures. The new peaks are marked by the asterisks. The IR modes abbreviations are the same as the Raman modes shown in Fig. 2. $\gamma\left(X Y_{2}\right): X Y_{2}$ twisting vibration about bisector of $Y-X-Y$ angle. 
asymmetric stretching display different frequency trends dependent on the pressures. The peak of low frequency moves to high wave number at a higher rate than the one of high frequency. Besides, during compression, two discontinuities are observed at $\sim 5 \mathrm{GPa}$ and $13 \mathrm{GPa}$ confirming the phase

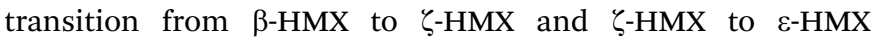
respectively. Additionally, according to Fig. S1b and $c, \uparrow$ the discontinuities emerge at $\sim 27 \mathrm{GPa}$. Several modes, $\nu_{\text {as }}\left(\mathrm{NNC}_{2}\right)$, $b(\mathrm{NNO}), \nu_{\text {as }}\left(\mathrm{NC}_{2}\right), \nu(\mathrm{NN}), \rho\left(\mathrm{CH}_{2}\right), \nu_{\text {as }}(\mathrm{CNN}), \nu_{\mathrm{as}}\left(\mathrm{NO}_{2}\right)$, and $\nu_{\mathrm{s}}\left(\mathrm{CH}_{2}\right)$ shift to low frequency obviously around $27 \mathrm{GPa}$ and then shift to high frequency again, which indicates another phase transition from $\eta$-HMX to $\phi$-HMX. The result agrees well with Raman spectra and XRD data indicated below.

\section{X-ray diffraction of $\beta$-HMX under non-hydrostatic pressure}

To investigate the structural variation of the phases under high pressure, XRD patterns of $\beta$-HMX under non-hydrostatic pressure were collected up to $40.7 \mathrm{GPa}$ (Fig. 5). All the peaks slowly shift to high-angle below $10.6 \mathrm{GPa}$ upon compression. Above 10.6 GPa, the -102 peak gradually shifts to low-angle, which corresponds to the phase transition to $\varepsilon$-HMX. At $16.9 \mathrm{GPa}$, a new peak marked by the asterisk emerges at low-angle, which evidences the phase transition to $\eta$-HMX. With further compression above $26.2 \mathrm{GPa}$, the -102 peak shifts to highangle. The -132 peak shifts to high-angle from 16.9 to 26.2 $\mathrm{GPa}$ at a very fast rate, and slows down above 26.2 GPa. These features are related to the phase transition to $\phi$-HMX. All of the diffractions are significantly weakened above $16.9 \mathrm{GPa}$, but still observable up to $40.7 \mathrm{GPa}$, indicating that the phase $\phi$ HMX remains stable up to $40.7 \mathrm{GPa}$. The XRD pattern of sample decompression from $40.7 \mathrm{GPa}$ is just the same as the starting

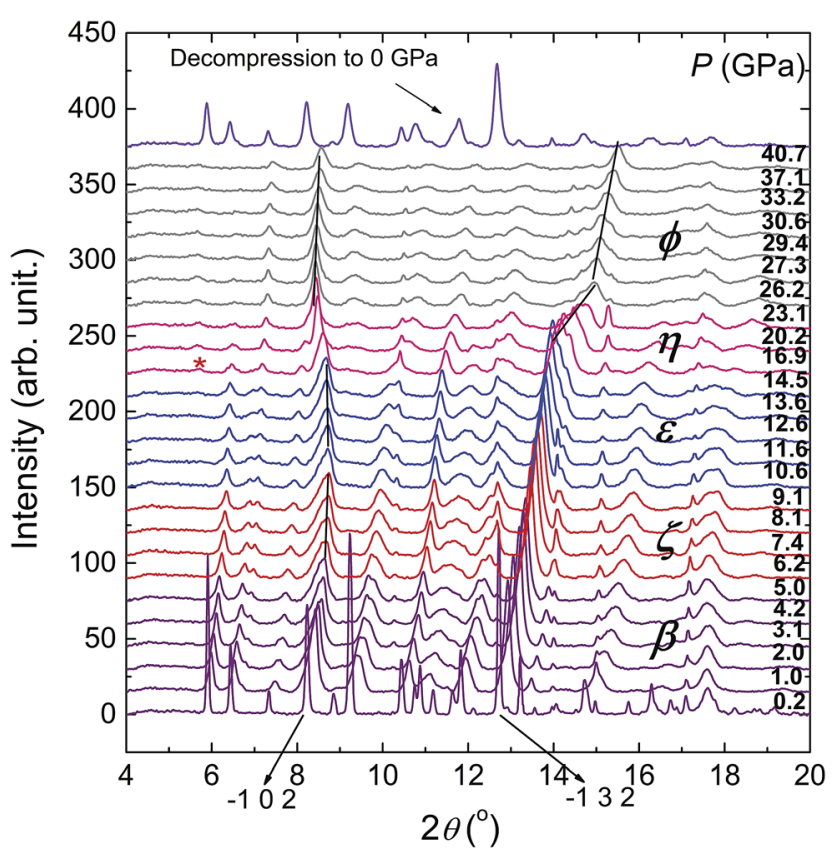

Fig. 5 XRD patterns of $\beta$-HMX under non-hydrostatic pressure up to $40.7 \mathrm{GPa}$ and ambient pressure after decompression. The corresponding phases are noted in the figure. material, which indicates these transitions are reversible. No chemical reaction can concluded from the compressiondecompression cycle.

Rietveld refinement was performed to determine the crystal structures. The original structural model of $\beta$-HMX are from a previous investigation $\left(P 22_{1} / n, a=6.54 \AA\right.$. $b=11.05 \AA$. $c=7.37$ $\left.\AA ; \beta=102.8^{\circ}\right) .{ }^{23}$ The lattice parameters from $0.2 \mathrm{GPa}$ to $14.5 \mathrm{GPa}$ are shown in Table S3† and Fig. 6 a. The $b$-axis has the highest compressibility. This is because several hydrogen bonds lie in or close to the ac-plane. The pressure depending unit cell volume was plotted and fitted using the $3^{\text {rd }}$ order Brich-Murnaghan equation of state: ${ }^{24,25}$

$$
\begin{aligned}
& P(V)= \\
& 1.5 B_{0}\left[\left(\frac{V_{0}}{V}\right) \frac{7}{3}-\left(\frac{V_{0}}{V}\right) \frac{5}{3}\right]\left\{1+\frac{3}{4}(B 1-4)\left[\left(\frac{V_{0}}{V}\right) \frac{2}{3}-1\right]\right\}
\end{aligned}
$$

$B_{0}$ and $B_{1}$ are ambient bulk modulus and its derivative, $V_{0}$ is the unit cell volume at ambient conditions, and all of them are released for fitting. As displayed in Fig. 6b, the volumes at 5.1 GPa and 10.6 GPa are discontinuous compared with other points, so we use two curves to fit the data, respectively. From $0.2 \mathrm{GPa}$ to $4.2 \mathrm{GPa}, V_{0}=521.6 \pm 3.5 \AA^{3}, B_{0}=14.4 \pm 4.2 \mathrm{GPa}, B_{1}=$ $12.8 \pm 5.5$. From 6.2 to $9.1 \mathrm{GPa}, V_{0}=482.7 \pm 1.4 \AA^{3}, B_{0}=65.1 \pm$
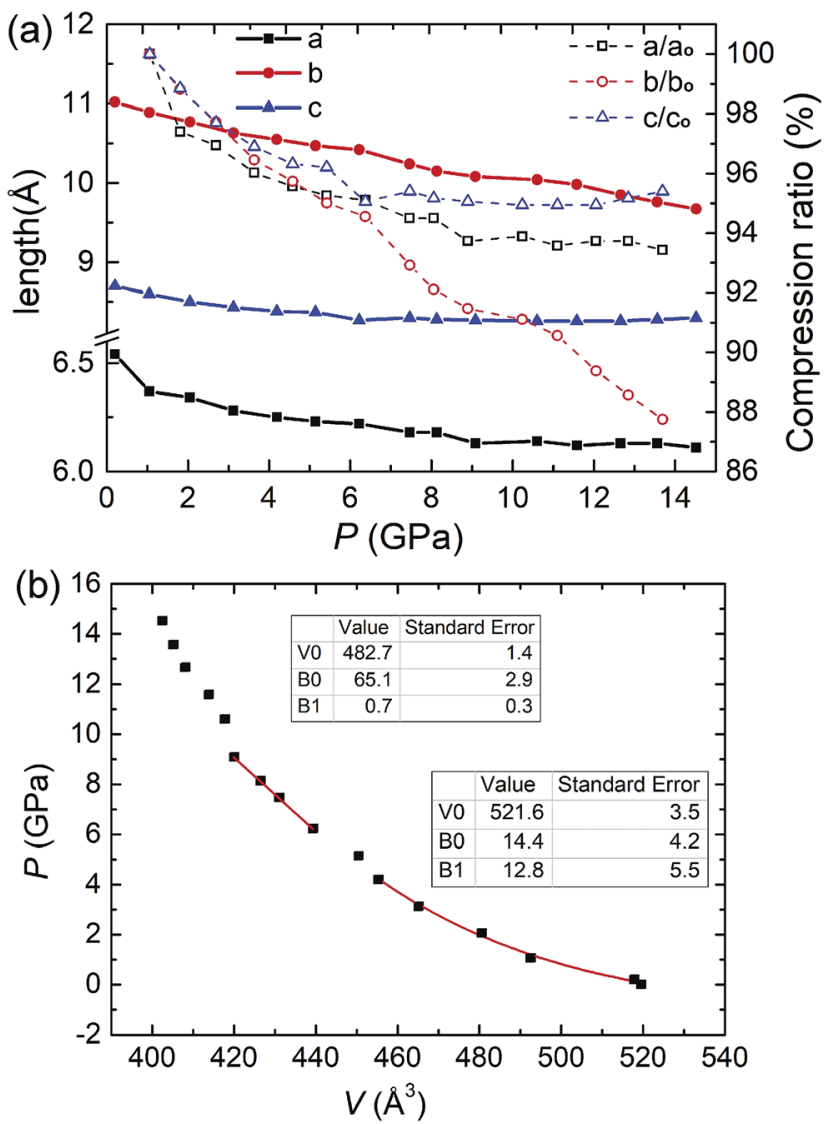

Fig. 6 (a) Variations in cell parameters as a function of pressures and compression ratios of three axes. (b) Equation of state of $\beta-\mathrm{HMX}$ under non-hydrostatic pressure. Two different lines are displayed in the figure. The error bar is smaller than the square. 
$2.9 \mathrm{GPa}, B_{1}+0.7 \pm 0.3$. The significant difference between the $V_{0}$ and $B_{0}$ values clearly indicates a phase transition from $\beta$-HMX to $\zeta$-HMX at around $5 \mathrm{GPa}$, which is in consistence with the spectral experiment. The unit cell of $\zeta$-HMX at $5.1 \mathrm{GPa}$ is $a=$ $6.233 \AA, b=10.474 \AA, c=8.369 \AA, \beta=124.49^{\circ}, P 2_{1} / c$. For the $\varepsilon^{-}$ HMX, the lattice parameters are $a=6.130 \AA$, $b=9.846 \AA$, $c=$ $8.258 \AA, \beta=125.06^{\circ}, P 2_{1} / c$ at $12.6 \mathrm{GPa}$. The atomic positions of $\zeta$-HMX and $\varepsilon$-HMX are displayed in Tables S4 and S5. $\dagger$ Above 10.6 GPa, the uncertainties of the refined parameters are too big to get reliable equation of state.

There are 10 crystallographic independent atoms (exclude hydrogen) in $\beta$-HMX, and hence 30 independent atomic coordinates ( $x, y$ and $z$ for each atom), which are too many to be fitted. To reduce the degree of freedoms, we introduced semirigid body in the refinement. The $\mathrm{N}-\mathrm{N}, \mathrm{N}-\mathrm{O}$ and $\mathrm{C}-\mathrm{N}$ bond length are restrained to $1.36 \AA$, $1.225 \AA$ and $1.45 \AA$. The bond angles of $\mathrm{O}-\mathrm{N}-\mathrm{O}$ and $\mathrm{O}-\mathrm{N}-\mathrm{N}$ are restrained to $120^{\circ}$. The bond angles of $\mathrm{C}-\mathrm{N}-\mathrm{C}, \mathrm{N}-\mathrm{C}-\mathrm{N}$ and $\mathrm{N}-\mathrm{N}-\mathrm{C}$ are restrained to $122^{\circ}, 111^{\circ}$ and $119^{\circ}$, respectively according to the literature. ${ }^{5}$ Hydrogen atoms were automatically added by the program and fixed on the carbon atoms. In the semi-rigid body, the $\mathrm{C}_{4} \mathrm{~N}_{4}$ ring is still free for distortion and the $\mathrm{NO}_{2}$ groups can also rotate, but the molecule won't be broken. Fig. 7a displays the molecular structures of ambient pressure and $6.2 \mathrm{GPa}$, respectively. Compared with that at ambient pressure, the molecular structure at $6.2 \mathrm{GPa}$ abruptly distorts. By measuring the angle between two skew lines $\left(\mathrm{C1}^{\prime}-\mathrm{C} 2\right.$ and $\left.\mathrm{O} 3-\mathrm{O} 4\right)$, we found the axial $\mathrm{NO}_{2}$ group rotates approximately $23.3^{\circ}$ around the $\mathrm{N}-\mathrm{N}$ bond compared with that at previous pressure point $(5.1 \mathrm{GPa}$, Fig. $\mathrm{S} 2 \dagger$ ). The rotation of $\mathrm{NO}_{2}$ group may be the direct reason or result of the $\beta-\zeta$ phase transition around $5 \mathrm{GPa}$.

The intermolecular and intramolecular hydrogen bonds (Fig. 7b) are closely associated with the moving of nitro groups.
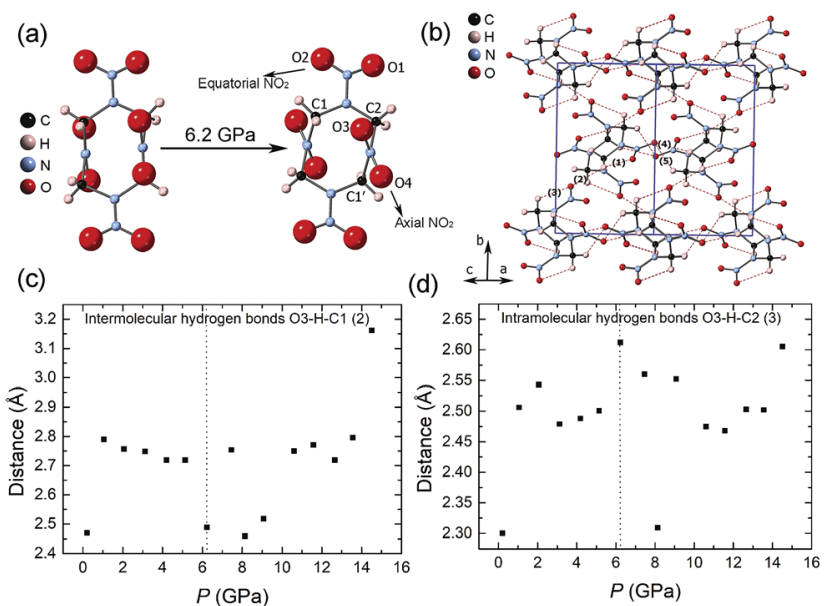

Fig. 7 Molecular structures of (a) ambient pressure (left) and 6.2 GPa (right). (b) Hydrogen bonds inside $\beta$-HMX crystal at ambient pressure. Red dotted lines represent hydrogen bonds. (1) and (3) are intramolecular hydrogen bonds. (2), (4) and (5) are intermolecular hydrogen bonds. Most hydrogen bonds approximately lie on the ac plane. (c) and (d) The lengths of hydrogen bonds $(\mathrm{O} \cdots \mathrm{H})$ (2) and (3) under high pressure.
The variations of five hydrogen bonds with pressure are shown in Fig. 7c, d and S3.† Compared with the intramolecular hydrogen bonds, the intermolecular hydrogen bonds are more compressible. Below $5.1 \mathrm{GPa}$, the lengths of hydrogen bonds change smoothly. At $6.2 \mathrm{GPa}$, the length of intermolecular hydrogen bonds related to $\mathrm{O} 3$ (hydrogen bond 2, Fig. 7c) decreases and the length of intramolecular hydrogen bonds related to $\mathrm{O} 3$ (hydrogen bond 3, Fig. 7d) increases abruptly, which indicates the axial nitro rotates at this pressure condition. Above $6.2 \mathrm{GPa}$, the lengths of hydrogen bonds are more diverging, which is likely to be related to the $\beta-\zeta$ phase transition and the changing of molecular conformation around $5 \mathrm{GPa}$.

\section{Decomposition of HMX under non-hydrostatic pressure condition and high temperature}

Because no chemical reaction of HMX is observed at high pressure (up to $40 \mathrm{GPa}$ ) and room temperature, we use diamond anvil cell (DAC) combing with resistive heating system to explore its chemical reaction under extreme conditions. Fig. 8 display the IR spectra of HMX under high pressure conditions after heating at $200{ }^{\circ} \mathrm{C}$ and $300{ }^{\circ} \mathrm{C}$. At $6.6 \mathrm{GPa}$, after heating at $200^{\circ} \mathrm{C}$, the pattern has no remarkable difference compared with the one before heating, suggesting no chemical reaction happened (Fig. 8a). By heating the sample at $300{ }^{\circ} \mathrm{C}$, as shown in the inset photos of Fig. 8a, the colour of HMX changes from white to black and the pressure changes from $6.6 \mathrm{GPa}$ to 8.7 GPa. All the signals of HMX disappeared and four new peaks were observed. The two peaks centered at $2396 \mathrm{~cm}^{-1}$ and $3767 \mathrm{~cm}^{-1}$ arise from the asymmetric stretch $\left(\nu_{3}\right)$ and the combination mode $\left(\nu_{1}+\nu_{3}\right)$ of solid $\mathrm{CO}_{2}$, respectively. ${ }^{26}$ The peaks appeared at $3500 \mathrm{~cm}^{-1}$ and $3200 \mathrm{~cm}^{-1}$ are tentatively assigned to the stretching of $-\mathrm{OH}$ and $-\mathrm{NH}$ or $-\mathrm{NOH}$ groups. ${ }^{27}$ The appearance of hydroxyl, imino and hydroxyimino groups indicates that the hydrogen transfer process is included in the decomposition process under high temperature and high pressure conditions. This is consistent with the ab inito study of HMX, which shows formation of the HONO group may be the initiation mechanism of the decomposition reaction. ${ }^{15}$ This hydrogen transfer process is also confirmed in the process of nitromentane decomposition under high static pressure and hydrogen transfer to form the aci-ion $\left(\mathrm{CH}_{2} \mathrm{NO}_{2}{ }^{-}\right)$mechanism is thus proposed. ${ }^{27}$

Upon decompression, the IR spectra of the decomposition product changes substantially as shown in Fig. 8b. When decompressed to $5.5 \mathrm{GPa}$, the peaks centered at $814 \mathrm{~cm}^{-1}$, $1095 \mathrm{~cm}^{-1}, 1314 \mathrm{~cm}^{-1}, 1469 \mathrm{~cm}^{-1}$ and $1628 \mathrm{~cm}^{-1}$ become more obvious and most of these peaks can still be observed when the DAC was open, which means these absorption bands come from the solid decomposition products. When the pressure decreases to $2.1 \mathrm{GPa}$, the peaks assigned to the $-\mathrm{OH}$ and $-\mathrm{NH}$ or $-\mathrm{NOH}$ groups develops to a broad peak centered at $3246 \mathrm{~cm}^{-1}$ and it disappears at $0.6 \mathrm{GPa}$ or opening the cell. This means these peaks related to the $-\mathrm{OH}$ and $-\mathrm{NH}$ or $-\mathrm{NOH}$ groups may come from highly volatile small molecules. The Raman spectrum of the remained black solid exhibits two broad bands centered at 

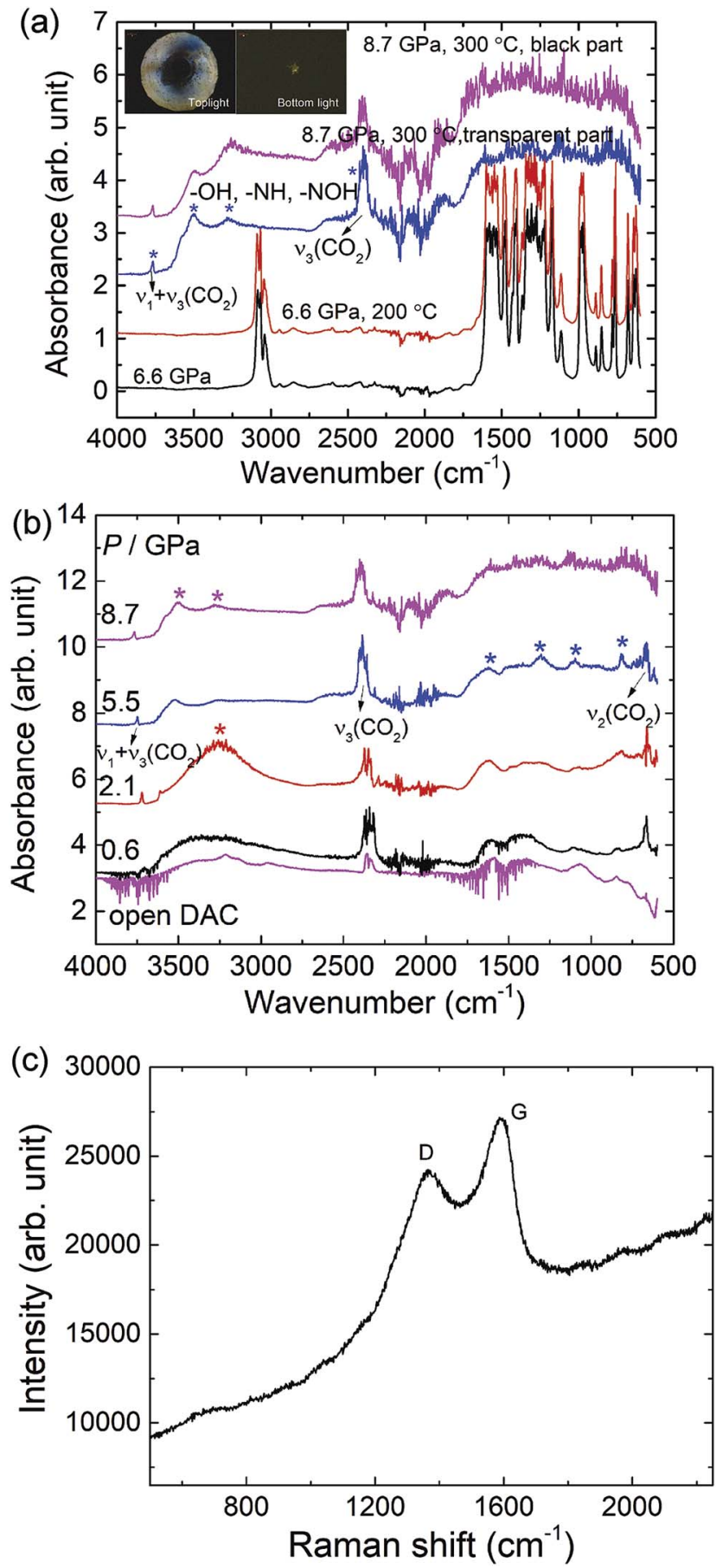

Fig. 8 (a) Infrared absorption spectra of HMX under high pressure, room temperature and after heating at $200{ }^{\circ} \mathrm{C}$ and $300{ }^{\circ} \mathrm{C}$. All the spectra were measured at room temperature. The black and transparent area can be observed after heating at $300^{\circ} \mathrm{C}$ and $8.7 \mathrm{GPa}$ (inset pictures); (b) the IR spectra of the transparent area during decompression process; (c) the Raman spectrum of the black product remained on the diamond culet after opening the DAC.

$1371 \mathrm{~cm}^{-1}$ and $1587 \mathrm{~cm}^{-1}$ at ambient conditions as shown in Fig. 8c, similar with the diamond (D) and graphite (G) of disordered graphite, ${ }^{28}$ which means the black product is most likely a framework material similar to that of a "disordered" graphite. $^{28}$

\section{Conclusion}

Combining with in situ Raman, IR spectroscopy, and X-ray diffraction, a systematic study of phase transitions and chemical reactions of $\beta$-HMX under high pressure and high temperature was conducted in this work. Four phases transitions at $5 \mathrm{GPa}(\zeta-\mathrm{HMX}), 12 \mathrm{GPa}(\varepsilon-\mathrm{HMX}), 16 \mathrm{GPa}$ ( $\eta$-HMX) and $27 \mathrm{GPa}(\phi$-HMX) were determined at high pressure and room temperature. The rotations of the $\mathrm{NO}_{2}$ groups under high pressure are related to the first phase transition $\beta-\zeta$ occurring around $5 \mathrm{GPa}$. All of them are reversible without any chemical reactions below $40 \mathrm{GPa}$. At $8.7 \mathrm{GPa}$ and $300{ }^{\circ} \mathrm{C}$, HMX decomposes to the disordered graphite like black product, highly volatile small molecules with $-\mathrm{OH},-\mathrm{NH}$ or $-\mathrm{NOH}$ groups and carbon dioxide. The decomposition process contains hydrogen transfer process. Our studies clarify the controversy on the phase transition of $\beta$-HMX under high pressure, especially the phase transition at $27 \mathrm{GPa}$, which has been a long hot debate. The decomposition products under extreme conditions were also given out and described in details. This will give new insights to understand the actual detonation process of energetic materials, which will be beneficial for designing new explosive materials with tailored properties.

\section{Conflicts of interest}

There are no conflicts to declare.

\section{Acknowledgements}

This work is supported by Science Challenge Project, no. TZ2016001. The authors also acknowledged the support of the National Nature Science Foundation of China (NSFC) (grant no. 21601007 and 21875006). The high pressure in situ X-ray diffraction was performed at 4W2 HP-Station, Beijing Synchrotron Radiation Facility (BSRF), which is supported by Chinese Academy of Sciences (Grant KJCX2-SW-N20, KJCX2-SW-N03). The authors also thank Dr Yanqing Wu for providing the $\beta$ HMX.

\section{Notes and references}

1 F. P. A. Fabbiani and C. R. Pulham, Chem. Soc. Rev., 2006, 35, 932-942.

2 W. C. Mccrone, Anal. Chem., 1950, 22, 1225-1226.

3 P. Main, R. E. Cobbledick and R. W. H. Small, Acta Crystallogr., 1985, C41, 1351-1354.

4 H. H. Cady, A. C. Larson and D. T. Cromer, Acta Crystallogr., 1963, 16, 617-623.

5 S. C. Chang and P. B. Henry, Acta Crystallogr., 1970, B26, 1235-1240.

6 R. E. Cobbledick and R. W. H. Small, Acta Crystallogr., 1974, B30, 1918-1922.

7 F. Goetz, T. B. Brill and J. R. Ferraro, J. Phys. Chem., 1978, 82, 1912-1917.

8 C.-S. Yoo and H. Cynn, J. Chem. Phys., 1999, 111, 10229. 
9 M. Pravica, M. Galley, E. Kim, P. Weck and Z. Liu, Chem. Phys. Lett., 2010, 500, 28-34.

10 D. E. Hare, J. W. Forbes, D. B. Reisman and J. J. Dick, Appl. Phys. Lett., 2004, 85, 949-951.

11 D. E. Hooks, D. B. Hayes, D. E. Hare, D. B. Reisman, K. S. Vandersall, J. W. Forbes and C. A. Hall, J. Appl. Phys., 2006, 99, 124901.

12 L.-Y. Lu, D.-Q. Wei, X.-R. Chen, G.-F. Ji, X.-J. Wang, J. Chang, Q.-M. Zhang and Z.-z. Gong, Mol. Phys., 2009, 107, 23732385.

13 L. Zhang, S.-L. Jiang, Y. Yu, Y. Long, H.-Y. Zhao, L.-J. Peng and J. Chen, J. Phys. Chem. B, 2016, 120, 11510-11522.

14 E. A. Glascoe, J. M. Zaug and A. K. Burnham, J. Phys. Chem. A, 2009, 113, 13548-13555.

15 D. Chakraborty, R. P. Muller, S. Dasgupta and W. A. Goddard, J. Phys. Chem. A, 2001, 105, 1302-1314.

16 G. J. Piermarini, S. Block and P. J. Miller, J. Phys. Chem., 1987, 91, 3872-3878.

17 C. Prescher and V. B. Prakapenka, High Pressure Res., 2015, 35, 223-230.
18 H. K. Mao, J. Xu and P. M. Bell, J. Geophys. Res., 1986, 91, 4673-4676.

19 V. Petricek, M. Dusek and L. Palatinus, Z. Kristallogr., 2014, 229, 345-352.

20 H. V. Brand, R. L. Rabie, D. J. Funk, I. Diaz-Acosta, P. Pulay and T. K. Lippert, J. Phys. Chem. B, 2002, 106, 10594-10604.

21 Y. Gu, K. Wang, Y.-X. Dai, G. Xiao, Y. Ma, Y. Qiao and B. Zou, J. Phys. Chem. Lett., 2017, 8, 4191-4196.

22 G. Qi, K. Wang, G. Xiao and B. Zou, Sci. China Chem., 2018, 61, 276-280.

23 P. F. Eiland and R. Pepinsky, Z. Kristallogr., 1955, 106, 273298.

24 F. Birch, Phys. Rev., 1947, 71, 809-824.

25 F. Birch, J. Geophys. Res.: Atmos., 1978, 83, 1257-1268.

26 R. Lu and A. M. Hofmeister, Phys. Rev. B: Condens. Matter Mater. Phys., 1995, 52, 3985-3992.

27 M. Citroni, R. Bini, M. Pagliai, G. Cardini and V. Schettino, J. Phys. Chem. B, 2010, 114, 9420-9428.

28 S. Reich and C. Thomsen, Philos. Trans. R. Soc., A, 2004, 362, 2271-2288. 